\title{
Breakfast habits affect overall nutrient profiles in adolescents
}

\author{
C Matthys $^{1, *}$, S De Henauw ${ }^{1,2}$, M Bellemans ${ }^{1}, M$ De Maeyer ${ }^{1}$ and G De Backer ${ }^{1}$ \\ 'Department of Public Health, De Pintelaan 185, Ghent University, B-9000 Ghent, Belgium: ${ }^{2}$ Department \\ of Health Sciences, Vesalius - Hogeschool Gent, Ghent, Belgium
}

Submitted 11 July 2005: Accepted 4 July 2006

\begin{abstract}
Objective: To describe breakfast consumption patterns, on a nutrient and food item level, in Belgian adolescents.

Design: A 7-day estimated food record was administered in a cross-sectional survey. Setting: Secondary schools in Ghent, Belgium.

Subjects: A total of 341 adolescents (13-18 years old), multistage clustered sampling. Results: The energy contribution of breakfast to daily energy intake was on average $15.7 \%$ in boys and $14.9 \%$ in girls. Significantly more overweight girls and significantly more girls following vocational training were categorised as eating a low-quality breakfast. In boys, the energy contribution of polysaccharides was significantly higher in consumers of good-quality breakfasts. The intake of all selected micronutrients was significantly higher in consumers of good-quality breakfasts. In girls, the total energy intake and the proportional intake of proteins and polysaccharides were significantly higher in consumers of good-quality breakfasts, while the proportional contribution of total fat, monounsaturated and polyunsaturated fatty acids was significantly lower in these girls. The intake of all micronutrients was significantly higher in girls consuming a good-quality breakfast. In all adolescents, consumers of a good-quality breakfast had significantly higher intakes of bread, fruit, vegetables, milk and milk products, and fruit juice, while intake of soft drinks was significantly lower than in consumers of low-quality breakfasts.

Conclusions: Consumers of a good-quality breakfast had a better overall dietary pattern - on a nutrient and food group level - than consumers of a low-quality breakfast. A daily breakfast, including whole-grain products, fruit and (semi-) skimmed milk products or an alternative source of calcium, is recommended.
\end{abstract}

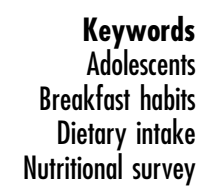

Keywords Breakfast habits uutritional survey
Breakfast is widely being promoted as essential for the nutritional well-being of children. Skipping breakfast is associated with health-compromising behaviours in adults and adolescents ${ }^{1}$. Breakfast consumers tend to have higher intakes of micronutrients and lower intake of fat, and are more likely to have a better overall diet quality ${ }^{2,3}$. The consumption of breakfast has been positively associated with enhanced cognitive and academic performance, psychosocial function and school attendance $^{4,5}$. However, other studies indicate that cognitive performance is relatively robust to short-term fasting in relatively well-nourished children ${ }^{6}$. Aranceta and co-workers stated that it is not clear to what extent breakfast contributes to a better cognitive performance in school. Learning is a complex process resulting from multiple interactions ${ }^{7}$. However, a recent review stated that breakfast may possibly benefit cognitive function, but the interpretation of the results can be complicated by confounding factors such as social and educational variables ${ }^{3}$.
It has been reported that routinely eating breakfast may lead to more regular eating habits and exercise patterns, healthy food choices and consistent energy intake, which when taken together contribute to a reduced body mass index $(\mathrm{BMI})^{8}$. Eating a healthy breakfast is important to adolescents' health needs in general. Breakfast provides an ideal opportunity for adolescents to begin the day by eating bread, other cereals and fruit, which are all important elements of a healthy and balanced diet. The importance of breakfast consumption in relation to nutritional balance has been shown in different sub-populations ${ }^{7,9,10}$. Despite the benefits of consumption of breakfast, it is the meal most often skipped by adolescents ${ }^{11}$.

In the present report, breakfast consumption patterns, on the nutrient and food item level, in Belgian adolescents are described. The analyses reported herein must be situated within a broad context of a search for elements that may be helpful for developing strategies to implement the translation of nutrient dietary guidelines into food- and meal-based dietary guidelines. 


\section{Materials and methods}

The data presented here were obtained from a crosssectional dietary survey carried out in an adolescent population (males and females aged 13-18 years) in the region of Ghent (Belgium) in the spring of 1997. The sampling design and the methodology of the field work have been described in detail elsewhere ${ }^{12}$. In brief, a random sample of 341 adolescents (129 boys and 212 girls) - selected from all educational levels in the Belgian secondary school system - completed a 7day food record (consecutive) under rigorous conditions of quality control carried out by experienced dietitians.

A 7-day estimated food record method (semi-structured diary) was used to quantify food and nutrient intake. Information on the type (including brand names) and amount of food consumed was collected through an open entry format. Instructions for the completion of the diary and regular checks for quality and completeness of the diaries were carried out by experienced dietitians. In the diaries, days were truncated into six eating moments, namely breakfast, lunch, dinner and snacks, the latter divided into morning, afternoon and late-evening snacks.

Breakfast was defined as the first eating occasion involving a solid food or a beverage that occurred after waking.

Nutrient composition data used in the current study are those from the Belgian and the Dutch food composition tables $^{13-15}$. Calculation of nutrients was done by means of a nutritional software package developed by the Unilever company in The Netherlands ${ }^{16}$. Average nutrient and food intakes were calculated as the mean of the 7-day intake period. Food items were classified into different food groups according to the Dutch food composition table ${ }^{13}$.

For the sake of the present analyses, a concise characterisation of the breakfast habits at the level of the individual was undertaken. This characterisation included both qualitative and quantitative aspects of breakfast. Qualitative aspects of breakfast were related to the presence or absence (in relevant amounts) of food items of three specific food groups (hereafter called 'target food groups'): cereal products, dairy products and fruit/vegetables. Quantitative aspects of breakfast included both the frequency of having breakfast and the relative contribution of the target food groups to the total daily energy from breakfast.

Qualitative and quantitative aspects of breakfast were combined into a so-called 'individual breakfast score' on the basis of the following consecutive steps.

In a first step, every single breakfast from all diaries was characterised in a qualitative way. For that purpose, 14 different labels were developed on the basis of different combinations of food groups present in the breakfast and the amount of energy they represented. These 14 labels were subsequently recoded into five specific individual breakfast labels' (see Table 1).

In a second step, the 'individual breakfast labels' were summed up for all days included in the food diary, resulting in a potential overall range of sumlabels from a minimum of seven (individual breakfast label of one for all days in the food diary) up to a maximum of 35 (individual breakfast label of five for each day in the food diary). From this 'sum-score', a final 'individual breakfast score' was assigned to all 341 subjects in the study (see Table 1).

For this study, the five individual breakfast score categories for breakfast habits were dichotomised into a group who 'never eats breakfast or eats a low-quality breakfast, i.e. not enough calories and/or not enough variation in foods' (group 1, score 1-3) and a group who 'eats a good-excellent-quality breakfast (nearly) every day' (group 2, score 4-5).

The ratio of energy intake to basal metabolic rate (EI/BMR) was calculated to give an indication of the quality of reporting ${ }^{17}$.

Table 1 Individual breakfast label and individual breakfast score

\begin{tabular}{|c|c|c|c|}
\hline \multicolumn{2}{|r|}{ Individual breakfast label } & \multicolumn{2}{|r|}{ Individual breakfast score } \\
\hline Number & Explanation & Number & Explanation \\
\hline Label 1 & No breakfast or very limited breakfast $(<400 \mathrm{~kJ})$ & Score 1 & $\begin{array}{l}\text { Subjects who never have any breakfast } \\
\text { of any significance (sum-score } 7-10 \text { ) }\end{array}$ \\
\hline Label 2 & Breakfast including only energy-containing beverages & Score 2 & $\begin{array}{l}\text { Subjects who usually do not have breakfast } \\
\text { of any significance (sum-score } 11-14 \text { ) }\end{array}$ \\
\hline Label 3 & $\begin{array}{l}\text { Breakfast including food items from one of the target food } \\
\text { groups, potentially in combination with a non-dairy fat or } \\
\text { protein source }\end{array}$ & Score 3 & $\begin{array}{l}\text { Subjects who either usually have breakfast } \\
\text { of low nutritional value or only occasionally } \\
\text { have breakfast of higher nutritional value } \\
\text { (sum-score 15-21) }\end{array}$ \\
\hline Label 4 & $\begin{array}{l}\text { Breakfast including food items from two of the target food groups, } \\
\text { potentially in combination with a non-dairy fat or protein source }\end{array}$ & Score 4 & $\begin{array}{l}\text { Subjects who usually have breakfast of } \\
\text { good/excellent nutritional value } \\
\text { (sum-score 22-29) }\end{array}$ \\
\hline Label 5 & $\begin{array}{l}\text { Breakfast including food items from the three target food groups, } \\
\text { potentially in combination with a non-dairy fat or protein source }\end{array}$ & Score 5 & $\begin{array}{l}\text { Subjects who eat good-excellent-quality } \\
\text { breakfast practically every day } \\
\text { (sum-score } 30-35 \text { ) }\end{array}$ \\
\hline
\end{tabular}


Statistical analysis was done with the SPSS software version 12 (SPSS Inc.). Descriptive statistics used means and standard deviations for continuous data. Tests for normality were performed using a Kolmogorov-Smirnov test. Student's $t$-tests or Mann-Whitney $U$-tests were used to compare the means of the different groups. In order to search for potential confounders, the number of adolescents in different categories of $\mathrm{BMI}^{18}$ and education 'general' education (mainly theoretical courses) and vocational training (based on practical skills) - in the different breakfast classifications were compared by use of a Fisher's exact test. A value of $<0.05$ was taken as the threshold for significance.

The study was approved by the Ethical Committee of the Ghent University Hospital.

\section{Results}

The energy contribution of breakfast to daily energy intake was on average $15.7 \%$ in boys and $14.9 \%$ in girls. A restricted number of boys and girls had a breakfast energy contribution of $>25 \%, 9.7 \%$ in boys and $5.7 \%$ in girls, respectively. Figure 1 shows the distribution of the energy contribution of breakfast to the total daily energy intake in both boys and girls.

Overall, the individual breakfast score was $<3$ (never eat or usually do not eat breakfast). In boys, $13.2 \%$ had an individual breakfast score $<3$, in girls $16.9 \%$ had an individual breakfast score $<3$. In boys, $\sim 18 \%$ ate a lowquality breakfast (score 3), $\sim 56 \%$ ate a 'moderate- to good-quality breakfast' (score 4), while only $13 \%$ ate a full value breakfast (score 5). In girls, $\sim 27 \%$ had an individual breakfast score of $3, \sim 45 \%$ had a score of 4 and only $10 \%$ had an individual breakfast score of 5 .

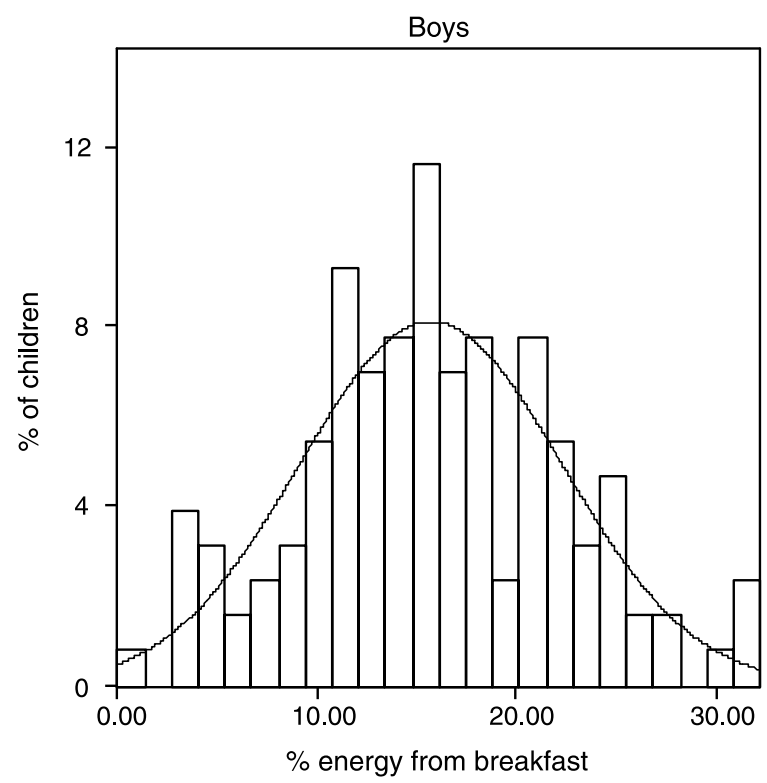

Table 2 presents the number of adolescents in different categories of BMI and education, and mean age and mean EI/BMR according to the different breakfast categories. In both boys and girls, a higher number of subjects were identified as good-quality breakfast eaters. In boys, the age of low-quality breakfast eaters was significantly higher than that of the good-quality breakfast eaters. In girls, the mean EI/ BMR ratio was significantly lower in low-quality breakfast consumers than in the subjects identified as good-quality breakfast consumers. In boys, no differences were found between breakfast categories according to BMI and educational training. Significantly more overweight girls and significantly more girls following a vocational training were categorised as low-quality breakfast consumers.

Table 3 shows the energy intake at breakfast, the energy contribution of macronutrients to the total energy supplied by breakfast and micronutrient intake at breakfast according to breakfast habits. In both boys and girls, the energy intake and the proportional contribution of proteins were significantly higher in subjects having a good-quality breakfast. Girls who consumed a good-quality breakfast had a significantly higher proportional intake of polysaccharides than the low-quality breakfast consumers. In both boys and girls, the intake at breakfast of the selected micronutrients was significantly higher in subjects consuming a good-quality breakfast.

In Table 4 total energy intake, the energy contribution of macronutrients to the total energy intake and micronutrient intake according to breakfast habits are presented. In boys, there was no significant difference in the total energy intake between the two kinds of breakfast consumers.

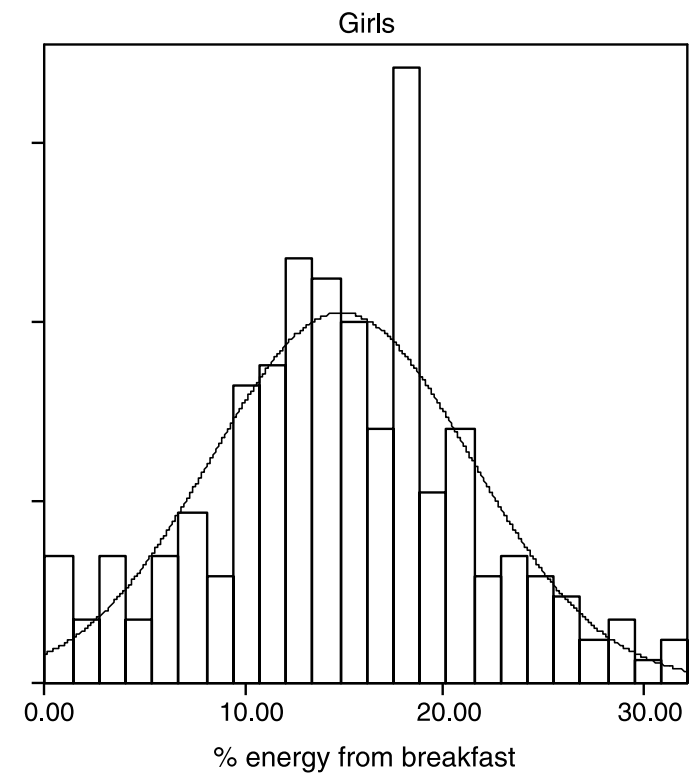

Fig. 1 Histograms showing the percentage energy from breakfast in boys and girls 
Table 2 The age, ratio of El/BMR and number of adolescents in different categories of BMI and education according to breakfast habit (low- or good-quality)

\begin{tabular}{|c|c|c|c|c|c|c|}
\hline & \multicolumn{2}{|c|}{ Boys $(n=129)$} & \multirow[b]{2}{*}{$P$-value } & \multicolumn{2}{|c|}{ Girls $(n=212)$} & \multirow[b]{2}{*}{$P$-value } \\
\hline & Low & Good & & Low & Good & \\
\hline$n$ & 40 & 89 & & 94 & 118 & \\
\hline Age (years)* & $16(1)$ & $15(1)$ & 0.013 & $16(1)$ & $16(1)$ & 0.482 \\
\hline $\mathrm{El} / \mathrm{BM}^{*}$ & $1.49(0.33)$ & $1.59(0.29)$ & 0.130 & $1.27(0.37)$ & $1.43(0.28)$ & $<0.001$ \\
\hline BMI†,‡,§ & & & $>0.999$ & & & 0.029 \\
\hline Normal & 38 & 83 & & 73 & 105 & \\
\hline Overweight & 2 & 6 & & 19 & 11 & \\
\hline Education§ & & & 0.400 & & & $<0.001$ \\
\hline General & 33 & 79 & & 25 & 76 & \\
\hline Vocational & 7 & 10 & & 69 & 42 & \\
\hline
\end{tabular}

El - energy intake; BMR - basal metabolic rate; BMI - body mass index.

Data for age and El/BMR presented as mean (standard deviation).

${ }^{*}$ Mann-Whitney U-test.

†BMI categories according to Cole et al. ${ }^{18}$.

¥Data of four girls are missing.

$\S$ Fisher's exact test.

The energy contribution of polysaccharides was significantly higher in good-quality breakfast consumers. The intake of all selected micronutrients was significantly higher in good-quality breakfast consumers.

In girls, the total energy intake was significantly higher in good-quality breakfast consumers. The proportional intake of proteins and polysaccharides was significantly higher in female good-quality breakfast consumers, while the proportional contribution of total fat, monounsaturated and polyunsaturated fatty acids was significantly lower in these girls. The intake of all micronutrients was significantly higher in girls consuming good-quality breakfast. In girls, the relative micronutrient intake (expressed as mg $1000 \mathrm{kcal}^{-1}$ ) was significantly higher in good-quality breakfast consumers (data not shown).

The intake of different food groups is presented in Table 5 . Both male and female adolescents who consumed a good-quality breakfast had significantly higher intakes of bread, fruit, vegetables, milk and milk products, and fruit juice, while their intake of soft drinks was significantly lower than those who consumed a low-quality breakfast. In girls, a larger number of differences were found. Female good-quality breakfast consumers also had significantly higher intakes of cereal products, cheese and water.

\section{Discussion}

The Iowa Breakfast Study carried out in the USA at the beginning of the 1960s was one of the first studies that addressed the importance of the role of breakfast in dietary balance, physical and cognitive performance ${ }^{19}$. To our knowledge, the present study is the first Belgian research on the relationship between breakfast parameters and the overall diet of adolescents. The current study found that

Table 3 Energy intake ( $\mathrm{kcal}$ ) at breakfast, contribution of macronutrients (as a percentage of energy) to the total energy supplied at breakfast and micronutrient intake (mg) at breakfast according to breakfast habit (low- or good-quality)

\begin{tabular}{|c|c|c|c|c|c|c|}
\hline & \multicolumn{2}{|c|}{ Boys $(n=129)$} & \multirow[b]{2}{*}{$P$-value* } & \multicolumn{2}{|c|}{ Girls $(n=212)$} & \multirow[b]{2}{*}{$P$-value* } \\
\hline & Low $(n=40)$ & Good $(n=89)$ & & Low $(n=94)$ & Good $(n=118)$ & \\
\hline Energy & $274.8(161.91)$ & $478.3(164.38)$ & $<0.001$ & $196.3(113.89)$ & $371.8(119.34)$ & $<0.001$ \\
\hline Protein & $10.7(4.56)$ & $12.4(2.81)$ & 0.022 & $12.1(6.42)$ & $14.1(3.47)$ & $<0.001$ \\
\hline Carbohydrates, total & $59.4(15.17)$ & $61.2(8.46)$ & 0.643 & 57.9 (18.34) & $60.1(9.20)$ & 0.335 \\
\hline Mono- and disaccharides & $32.3(16.43)$ & $30.6(8.57)$ & 0.699 & $34.3(20.08)$ & $30.3(9.76)$ & 0.389 \\
\hline Polysaccharides & 26.8 (12.51) & $30.1(8.18)$ & 0.278 & $23.4(15.36)$ & 29.7 (9.62) & 0.002 \\
\hline Fat, total & $27.3(12.98)$ & $26.3(8.07)$ & 0.492 & $25.6(13.06)$ & $25.7(7.71)$ & 0.519 \\
\hline SFA & $12.4(6.96)$ & $11.2(4.50)$ & 0.562 & $11.1(6.26)$ & $11.3(4.44)$ & 0.941 \\
\hline MUFA & $8.7(5.08)$ & $8.3(3.20)$ & 0.533 & $8.4(4.98)$ & $8.0(3.05)$ & 0.334 \\
\hline PUFA & $3.8(3.62)$ & $3.9(2.83)$ & 0.418 & $3.9(3.30)$ & $3.5(1.90)$ & 0.775 \\
\hline Calcium & $112.7(98.86)$ & $261.5(145.54)$ & $<0.001$ & $108.1(105.60)$ & $248.5(147.35)$ & $<0.001$ \\
\hline Phosphorus & 154.8 (111.99) & $323.1(144.62)$ & $<0.001$ & $125.6(107.44)$ & $291.9(157.57)$ & $<0.001$ \\
\hline Iron & $1.6(1.11)$ & $2.7(1.40)$ & $<0.001$ & $0.9(1.03)$ & $2.1(1.16)$ & $<0.001$ \\
\hline Magnesium & $33.1(22.64)$ & $66.8(30.25)$ & $<0.001$ & $25.7(17.71)$ & $56.8(27.54)$ & $<0.001$ \\
\hline Thiamin & $0.2(0.11)$ & $0.3(0.19)$ & $<0.001$ & $0.1(0.12)$ & $0.3(0.16)$ & $<0.001$ \\
\hline Riboflavin & $0.2(0.19)$ & $0.5(0.31)$ & $<0.001$ & $0.2(0.21)$ & $0.5(0.29)$ & $<0.001$ \\
\hline Vitamin C & $3.2(8.61)$ & 17.1 (25.95) & $<0.001$ & $7.9(14.28)$ & $18.1(21.27)$ & $<0.001$ \\
\hline
\end{tabular}

SFA - saturated fatty acids; MUFA - monounsaturated fatty acids; PUFA - polyunsaturated fatty acids.

Data presented as mean (standard deviation).

Mann-Whitney $U$ tests. 
Table 4 Total energy intake (kcal), contribution of macronutrients (as a percentage of energy) to the total energy and micronutrient intake (mg) according to breakfast habit (low- or good-quality)

\begin{tabular}{|c|c|c|c|c|c|c|}
\hline & \multicolumn{2}{|c|}{ Boys $(n=129)$} & \multirow[b]{2}{*}{$P$-value } & \multicolumn{2}{|c|}{ Girls $(n=212)$} & \multirow[b]{2}{*}{$P$-value* } \\
\hline & Low $(n=40)$ & Good $(n=89)$ & & Low $(n=94)$ & Good $(n=118)$ & \\
\hline Energy & 2603.9 (577.33) & 2674.8 (488.20) & 0.502 & $1841.2(494.96)$ & 2072.9 (384.72) & $<0.001$ \\
\hline Protein & $13.9(1.84)$ & $14.6(2.08)$ & 0.058 & $14.1(2.71)$ & $15.5(2.37)$ & $<0.001$ \\
\hline Carbohydrates, total & $47.8(5.28)$ & $49.2(4.81)$ & 0.140 & $48.7(6.06)$ & $49.6(4.92)$ & 0.266 \\
\hline Mono- and disaccharides & $22.0(6.74)$ & $22.7(5.04)$ & 0.596 & $22.6(7.02)$ & $22.7(4.86)$ & 0.831 \\
\hline Polysaccharides & $22.0(4.06)$ & $24.0(4.36)$ & 0.016 & $22.9(5.17)$ & $24.4(4.22)$ & 0.025 \\
\hline Fat, total & $36.8(4.64)$ & $35.9(4.49)$ & 0.327 & $36.5(5.44)$ & 34.6 (4.39) & 0.005 \\
\hline SFA & $14.6(2.54)$ & $14.6(2.33)$ & 0.990 & $14.6(2.42)$ & $14.3(2.22)$ & 0.386 \\
\hline MUFA & $14.3(2.30)$ & $13.6(2.17)$ & 0.120 & $14.1(2.81)$ & $12.7(2.17)$ & $<0.001$ \\
\hline PUFA & $6.0(1.48)$ & $5.7(1.59)$ & 0.288 & $5.9(1.62)$ & $5.4(1.25)$ & 0.005 \\
\hline Calcium & 739.9 (277.44) & 991.4 (351.52) & $<0.001$ & $638.3(278.96)$ & 937.8 (347.02) & $<0.001$ \\
\hline Phosphorus & 1315.6 (291.61) & $1543.3(363.79)$ & 0.001 & 979.9 (283.37) & 1304.5 (373.22) & $<0.001^{*}$ \\
\hline Iron & $12.6(2.64)$ & $13.8(2.97)$ & 0.035 & $8.9(2.45)$ & $10.9(2.75)$ & $<0.001$ \\
\hline Magnesium & $233.9(52.30)$ & $288.1(70.28)$ & $<0.001$ & $179.2(48.49)$ & $242.3(65.30)$ & $<0.001$ \\
\hline Thiamin & $1.3(0.37)$ & $1.6(0.87)$ & $0.004^{*}$ & $0.9(0.74)$ & $1.3(1.00)$ & $<0.001^{\mathrm{a}}$ \\
\hline Riboflavin & $1.4(0.39)$ & $1.8(0.58)$ & $<0.001$ & $1.1(0.53)$ & $1.5(0.56)$ & $<0.001$ \\
\hline Vitamin C & $56.5(27.80)$ & $94.5(51.88)$ & $<0.001^{*}$ & $64.1(42.64)$ & 89.5 (46.35) & $<0.001^{a}$ \\
\hline
\end{tabular}

SFA - saturated fatty acids; MUFA - monounsaturated fatty acids; PUFA - polyunsaturated fatty acids.

Data presented as mean (standard deviation).

*Mann-Whitney U-test.

consumers of a good-quality breakfast had a better overall dietary pattern - on the nutrient and food group level - than consumers of low-quality breakfast. However, the current differences in dietary intake could not be related to nutrient status due to the lack of biochemical assays of cholesterol, vitamin and mineral status. Nevertheless, the associations between breakfast patterns and biomarkers of nutrient status are not widely reported and are inconsistent. Preziosi and colleagues only found a significantly higher blood thiamin concentration in adolescents consuming highenergy breakfasts ${ }^{20}$.

In the current study, some methodological considerations have to be taken into account. In this study, individual breakfast labels and scores were computed. These breakfast scores were based on both nutrient and food item recommendations. However, there is no general scientific agreement as to which foods have to be consumed and in what amounts. Therefore, the current rationale for the development of the scores is two-fold. For food items, the rationale is based on the guidelines for a healthy breakfast in schoolchildren ${ }^{21,22}$ and for energy the rationale is based on the assumption that an ideal breakfast should provide at least $25 \%$ of the recommended daily energy ${ }^{9,23}$. This recommendation is based on the above-mentioned Iowa Breakfast Study ${ }^{19}$. In addition, by introducing a breakfast score, the authors are aware that a limitation could be introduced due to the lack of information about the heterogeneity and variability of the breakfast consumption pattern of all adolescents, both within and between the good- and low-quality breakfast consumers. As the classification method can group subjects with widely differing intakes into one category and subjects with very similar intakes into different categories if they are close to the cut-off point, this could introduce difficulties for the interpretation of the results. Another possible disadvantage of the breakfast score algorithm used is that a subject receives a lower score when he/she does not consume one of the selected foods. A methodological issue that also has to be taken into account is the sample size. The total sample size contains more girls than boys. The limited number of boys could cause a lack of power in the analyses. The originally selected sample contained fewer boys than girls. This could be explained by the study design where male-only schools were less well represented. It is not clear in what way this may have affected the results of the study but it does not affect the value of the within-gender analyses. However, the strength of the current study is the use of the 7-day dietary record, which reflects the usual dietary intake and reflects in that way the usual breakfast consumption of the different participants. It is not clear how the possible impact of the possible limitations may have affected the results of the study.

The importance of breakfast in ensuring adequate nutrient intake in children and adolescents has been documented in different studies ${ }^{7,20,24-26}$. The current findings, i.e. that consumers of a good-quality breakfast have a better overall dietary pattern than those who consume a low-quality breakfast, are in line with these European studies. However, an inherent problem with comparing different breakfast studies are the methodological differences regarding dietary intake data collection and how breakfast is defined (types, amounts, categories). These inconsistencies should be kept in mind when comparing different studies. In the current study, female good quality breakfast consumers have a higher energy intake, while no difference was found in boys. In the Göteborg Adolescence Study (15-16 years), a similar trend was found, i.e. female adolescents eating breakfast on 


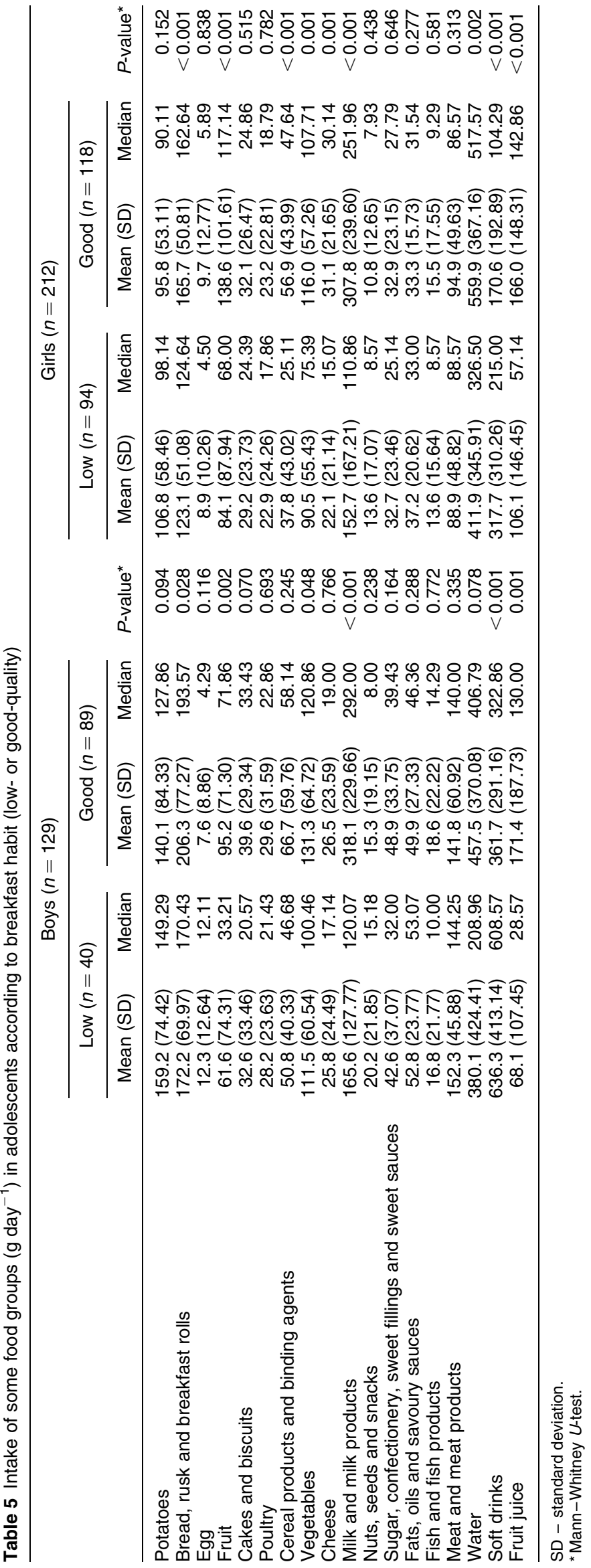


a regular basis had significantly higher energy intake compared with those with irregular breakfast intake ${ }^{11}$. In the current study, female good-quality breakfast consumers had a relative higher intake of total protein and polysaccharides, and a relative lower intake of total fat, monounsaturated fatty acids and polyunsaturated fatty acids. In boys, only a relative higher intake of polysaccharides in good-quality breakfast consumers was found. In a French study, adolescents (1018 years) consuming a high-energy breakfast ( $>25 \%$ of energy from breakfast) had higher total daily intakes (expressed as percentage energy) of carbohydrates but lower intake of total fat and saturated fat than their counterparts $^{20}$. Swedish regular breakfast consumers had a higher relative intake of total protein and a lower relative intake of sucrose ${ }^{11}$. However, in the literature, conflicting results can be found. De Graaf and co-workers showed that neither energy content nor macronutrient composition of breakfast had any effect on energy and macronutrient intake consumed over the rest of the day ${ }^{27}$.

Good-quality breakfast consumers have a higher intake of micronutrients. In a French, Spanish and Swedish adolescent population, the intake of vitamin C, thiamin, riboflavin, calcium, iron and zinc was higher in regular breakfast consumers (Sweden) or high-energy breakfast consumers (France, Spain) ${ }^{11,20,26}$. Adolescents eating a low-quality breakfast seem not to be able to make up the low micronutrient intake at other meals during the day. In a recent review, all the above findings are reflected and it is clear that there is evidence that breakfast consumption significantly contributes to the overall nutrient adequacy of the diet ${ }^{3}$.

In the current study, in girls, the group who consume a good-quality breakfast is associated with a lower proportion of overweight adolescents, despite the higher daily energy intake. Skipping breakfast is a popular method of losing weight among adolescents ${ }^{28}$ and it is shown that adolescents who have the perception of a too high body weight may be more likely to skip breakfast ${ }^{11}$. Skipping breakfast may lead to hunger in the morning and result in increased snacking. From a public health point of view, this phenomenon of increased snacking should be associated with a higher consumption of whole-grain products, fruit, vegetables and water. Unfortunately, snack foods commonly consumed by adolescents tend to be high in added sugars and fat, and low in minerals and vitamins. This could lead to a less healthy dietary pattern. In addition, the food availability at schools could play a role in this increased consumption of 'empty calories'. A recent study showed that the majority of the food items available in schools, supplied by school shops or vending machines, could be categorised as 'empty calories' ${ }^{29}$. Due to these factors, i.e. skipping breakfast, increased snacking on 'empty calories', the availability of poor-quality food items and weight gain, adolescents could get caught in a 'vicious circle'. However, based on several cross-sectional studies, no uniform association between skipping breakfast and higher weight or BMI is found in adolescents ${ }^{3}$. Some studies, however, state that breakfast consumption is part of a weightreduction programme ${ }^{30}$ and it is one of the factors affecting weight-loss maintenance in adults ${ }^{31}$. However, to date, to our knowledge, there have been no randomised controlled trials investigating breakfast consumption and weight control in adolescents. Breakfast consumption, a regular meal rhythm and an increase in feeding frequencies seem to have a positive impact on weight management ${ }^{32}$. However, there is no scientific consensus about specific recommendations concerning meal frequency and health outcomes ${ }^{33,34}$.

Good-quality breakfast consumers tend to make more healthy food choices during the day, such as the consumption of more vegetables, fruit, milk and milk products, and water, and a lower consumption of soft drinks. The significantly higher intake of milk and milk products and cheese in female good-quality breakfast consumers is possibly the main contributors of the higher saturated fatty acid intake. A similar pattern was found in Swedish adolescents; girls with irregular breakfast and lunch intake make less healthy food choices and consume more soft drinks and less milk, vegetables and fruit ${ }^{11}$.

Several studies have mentioned the importance of ready-to-eat breakfast cereals; the nutritional benefits of these cereals are associated with improved compliance with dietary recommendations and improved nutrient status based on biochemical measures ${ }^{35,36}$. In the current study, $<50 \%$ of the adolescents consumed ready-to-eat breakfast cereals and the average portion size was $<20 \mathrm{~g}$. As the intake of these food items is rather small, the influence of these cereals could be neglected in this study.

Several authors emphasise the importance of breakfast and that it should be included in educational programmes promoting healthy diets and lifestyles ${ }^{37}$ or even included in school-based nutrition education programmes, involving families, teachers and others in achieving healthier patterns ${ }^{7}$. In the UK, the Department of Health initiated breakfast club schemes in schools. Breakfast clubs are a form of before-school provision serving food to children who arrive early. The main aims of the scheme were to provide breakfast to children who might otherwise not have eaten, to establish a positive relationship at the start of the school day and to offer children a choice of healthy food, which may help to encourage healthier eating habits. However, a recent study indicates that children who attend breakfast clubs have a poorer nutrient intake than other children at the same schools ${ }^{38}$. It has been shown that parents eating breakfast is associated with adolescents eating breakfast. This suggests that breakfast programmes that address the whole family or just parents may be more effective ${ }^{1}$.

The present results and the literature show that the nutritional profile of Belgian adolescents could be substantially improved by the consumption of a healthy breakfast in a family setting on a daily basis, consisting of a 
variety of foods, namely whole-grain products, fruit and (semi-) skimmed milk products or an alternative source of calcium.

\section{Acknowledgements}

The original food consumption survey was financially supported by the National Fund for Scientific Research (fund no. 31557898), the Kellogg's Benelux Company, Unilever Belgium, the Belgian Nutrition Information Center and the 'Vlaams Wetenschappelijk Fonds'.

\section{References}

1 Keski-Rahkonen A, Kaprio J, Rissanen A, Virkkunen M, Rose RJ. Breakfast skipping and health-compromising behaviors in adolescents and adults. European Journal of Clinical Nutrition 2003; 57: 842-53.

2 Ruxton $\mathrm{CH}$, Kirk TR. Breakfast: a review of associations with measures of dietary intake, physiology and biochemistry. British Journal of Nutrition 1997; 78: 199-213.

3 Rampersaud GC, Pereira MA, Girard BL, Adams J, Metzl JD. Breakfast habits, nutritional status, body weight, and academic performance in children and adolescents. Journal of American Dietetic Association 2005; 105: 743-60.

4 Pollitt E. Does breakfast make a difference in school? Journal of the American Dietetic Association 1995; 95: 1134-9.

5 Pollitt E, Mathews R. Breakfast and cognition: an integrative summary. American Journal of Clinical Nutrition 1998; 67: 804S-13S.

6 Rogers PJ. How important is breakfast? British Journal of Nutrition 1997; 78: 197-8.

7 Aranceta J, Serra-Majem L, Ribas L, Perez-Rodrigo C. Breakfast consumption in Spanish children and young people. Public Health Nutrition 2001; 4: 1439-44.

8 Affenito SG, Thompson DR, Barton BA, Franko DL, Daniels SR, Obarzanek E, et al. Breakfast consumption by AfricanAmerican and white adolescent girls correlates positively with calcium and fiber intake and negatively with body mass index. Journal of the American Dietetic Association 2005; 105: 938-45.

9 Morgan KJ, Zabik ME, Stampley GL. The role of breakfast in diet adequacy of the U.S. adult population. Journal of American College of Nutrition 1986; 5: 551-63.

10 Navia B, Requejo AM, Ortega RM, Lopez Sobaler AM, Quintas ME, Andres $\mathrm{P}$, et al. The relationship between breakfast and whole diet energy profiles in a group of preschool children. Annals of Nutrition \& Metabolism 1997; 41: 299-306.

11 Sjoberg A, Hallberg L, Hoglund D, Hulthen L. Meal pattern, food choice, nutrient intake and lifestyle factors in The Goteborg Adolescence Study. European Journal of Clinical Nutrition 2003; 57: 1569-78.

12 Matthys C, De Henauw S, Devos C, De Backer G. Estimated energy intake, macronutrient intake and meal pattern of Flemish adolescents. European Journal of Clinical Nutrition 2003; 57: 366-75.

13 NEVO. NEVO Tabel, Nederlands Voedingsstoffenbestand. Zeist: NEVO, 1993.

14 NUBEL. Belgische Voedingsmiddelentabel. Brussels: Ministerie van Volksgezondheid, 1992.

15 NUBEL. Belgische Voedinsmiddelentabel, Tweede Uitgave. Brussels: Ministerie van Volksgezondheid, 1995.

16 Unilever. Becel Voedingsprogramma. Rotterdam: Nederlandse Unilever Bedrijven BV, 1992.
17 Goldberg GR, Black AE, Jebb SA, Cole TJ, Murgatroyd PR, Coward WA, et al. Critical evaluation of energy intake data using fundamental principles of energy physiology: 1 . Derivation of cut-off limits to identify under-recording. European Journal of Clinical Nutrition 1991; 45: 569-81.

18 Cole TJ, Bellizzi MC, Flegal KM, Dietz WH. Establishing a standard definition for child overweight and obesity worldwide: international survey. British Medical Journal 2000; 320: $1240-3$.

19 Cereal Institute Inc. A Complete Summary of the Iowa Breakfast Studies. Chicago, IL: Cereal Institute Inc., 1962.

20 Preziosi P, Galan P, Deheeger M, Yacoub N, Drewnowski A, Hercberg S. Breakfast type, daily nutrient intakes and vitamin and mineral status of French children, adolescents, and adults. Journal of American College of Nutrition 1999; 18: $171-8$

21 Pérez-Rodrigo C, Ribas Barba L, Serra Majem L, Aranceta Bartina J. Recomendaciones para un desayuno saludable. In: Serra Majem L, Aranceta Bartina J, eds. Desayno y Equilibro Alimentario. Barcelona: Masson, 2000; 91-7.

22 Vlaams Instituut voor Gezondheidspromotie. De Voedingsdrieboek: Een Praktische Voedingsgids [The Food Triangle: A Practical Guide]. Brussels: Vlaams Instituut voor Gezondheidspromotie, 2003.

23 Morgan KJ, Zabik ME, Leveille GA. The role of breakfast in nutrient intake of 5- to 12-year-old children. American Journal of Clinical Nutrition 1981; 34: 1418-27.

24 Hercberg S, Preziosi P, Galan P, Yacoub N, Kara G, Deheeger M. La consumation du petit-déjeuner dans l'étude du Val-DeMarne. 3. La valeur nutritionelle du petit-déjeuner et ses relations avec l'équilibre nutritionnel global et le statut minéral et vitaminique. Cahier Nutritionelle et Diététique 1996; 31(Suppl. 1): 18-24.

25 Baric IC, Satalic Z. Breakfast quality differences among children and adolescents in Croatia. International Journal of Food Science and Nutrition 2002; 53: 79-87.

26 Ortega RM, Requejo AM, Lopez-Sobaler AM, Andres P, Quintas ME, Navia B, et al. The importance of breakfast in meeting daily recommended calcium intake in a group of schoolchildren. Journal of American College of Nutrition 1998; 17: 19-24.

27 De Graaf C, Hulshof T, Weststrate JA, Jas P. Short-term effects of different amounts of protein, fats, and carbohydrates on satiety. American Journal of Clinical Nutrition 1992; 55: 33-8.

28 Lattimore PJ, Halford JC. Adolescence and the diet-dieting disparity: healthy food choice or risky health behaviour? British Journal of Health Psychology 2003; 8: 451-63.

29 Vereecken CA, Bobelijn K, Maes L. School food policy at primary and secondary schools in Belgium-Flanders: does it influence young people's food habits? European Journal of Clinical Nutrition 2005; 59: 271-7.

30 Schlundt DG, Hill JO, Sbrocco T, Pope-Cordle J, Sharp T. The role of breakfast in the treatment of obesity: a randomized clinical trial. American Journal of Clinical Nutrition 1992; 55: $645-51$.

31 Elfhag K, Rossner S. Who succeeds in maintaining weight loss? A conceptual review of factors associated with weight loss maintenance and weight regain. Obesity Reviews 2005; 6: $67-85$.

32 Louis-Sylvestre J, Lluch A, Neant F, Blundell JE. Highlighting the positive impact of increasing feeding frequency on metabolism and weight management. Forum Nutrition 2003; 56: $126-8$.

33 Mattson MP. The need for controlled studies of the effects of meal frequency on health. Lancet 2005; 365: 1978-80.

34 Gibney MJ, Wolever TM. Periodicity of eating and human health: present perspective and future directions. British Journal of Nutrition 1997; 77(Suppl 1): S3-5.

35 Gibson S. Micronutrient intakes, micronutrient status and lipid profiles among young people consuming different 
amounts of breakfast cereals: further analysis of data from the National Diet and Nutrition Survey of Young People aged 4 to 18 years. Public Health Nutrition 2003; 6: 815-20.

36 Galvin MA, Kiely M, Flynn A. Impact of ready-to-eat breakfast cereal (RTEBC) consumption on adequacy of micronutrient intakes and compliance with dietary recommendations in Irish adults. Public Health Nutrition 2003; 6: $351-63$.
37 Gassin AL. Helping to promote healthy diets and lifestyles: the role of the food industry. Public Health Nutrition 2001; 4 : $1445-50$.

38 Belderson P, Harvey I, Kimbell R, O'Neill J, Russell J, Barker ME. Does breakfast-club attendance affect schoolchildren's nutrient intake? A study of dietary intake at three schools. British Journal of Nutrition 2003; 90: 1003-6. 